\title{
Information Effects and Mass Support for EU Policy Control
}

\author{
Nick Clark \\ Indiana University \\ nijclark@indiana.edu
}

\author{
Timothy Hellwig \\ Indiana University \\ thellwig@indiana.edu
}

February 21, 2011

\begin{abstract}
The European Union, it is often noted, suffers from a democracy deficit. Most critiques of EU democracy focus on problems of institutional design, such as the distance between the European public and the EU policy-making bodies, or behavioral factors like participation in European Parliament elections. However, democracy also requires an active and informed citizenry. In this paper, we examine the impact of an informed public on support for European-level policy competencies. Is public skepticism of EU authority shaped by a lack of knowledge, or are preferences over the locus of policy control unbiased by information? Our analysis of mass preferences for policy control over 27 issue areas reveals that, in every case, a paucity of knowledge about the EU depresses popular support for European policy jurisdiction. Further analyses show that possessing of information about Europe affects supports for EU control in issue areas clearly involving cross-border or regional problems rather than areas associated with the Single Market
\end{abstract}

Paper prepared for delivery at the European Union Studies Association $12^{\text {th }}$ Biennial International Conference, Boston, March 3-5, 2011

The authors are grateful for support from the Andrew W. Mellon Foundation and the Department of West European Studies at Indiana University 


\section{Introduction}

The European Community has long suffered from a “democratic deficit” (Williams 1991, Majone 2000, Follesdal \& Hix 2006), posing a clear crisis of legitimacy for the European project (van der Eijk and Franklin 2004). One of the potential sources of this deficit, cited by both the Commission and critics of democracy in the European Union (EU) alike, is the absence of a European “public sphere” (Scharpf 1999, Siedentop 2000, Schmitter 2000, Habermas 2001a) through which citizens might learn more about how Europe works and the costs and benefits of European integration. This claim presumes that a better informed European citizenry would, with time, build up a much needed reservoir of support for European integration and, in particular, European-level policy competencies. Yet despite widespread concern and debate over the democracy deficit, and despite what we know about the publics' lack of political knowledge, no study has taken up the policy implications of a more informed citizenry for mass support for the European project.

There is ample reason to believe that, in terms of policy preferences, a more informed set of member state publics would make a difference. As Converse (1964) noted some years ago, the public’s knowledge of politics is characterized by a low mean and high variance. And as analyses of election studies data have found, this defining characteristic of national electorates has implications for political behavior and, in the aggregate, election results (Bartels 1996; Blais et al. 2009). Individuals require political information to identify and articulate policy preferences that accurately reflect their political pre-dispositions. Consequently, the ill-informed may advocate positions that are not in line with their values and interests. To the extent that public opinion polls — the means for assessing the public's policy preferences — captures such ill- 
informed positions, the resulting aggregation of mass opinions may not be reflective of the actual interests of the ill-informed segments of society (Althaus 1998; 2003; Gillens 2001).

The dearth of easily-available information about the EU may exacerbate these information biases at the European level. The EU lacks the quantity and quality of media coverage and political discourse found at the national level (Meyer 1999, de Vreese, et al 2006), denying the ill-informed with heuristics for developing positions on EU issues that accurately reflect their interests. And the EU's multilevel character, coupled with asymmetries in the extent to which it exerts power over policy, makes EU decision-making considerably more complex than most national political systems (Schmitter 2000, Christiansen 2001, Chabert 2002). Moreover, developing unbiased positions on European matters requires citizens to blend and balance considerations in domestic and foreign policy.

If information effects exist, than in what way is EU opinion biased? We argue that collective preferences are actually more supportive of European integration than often suggested by survey data on European integration. Much of the available elite and media discourse about the EU emphasizes the drawbacks of European integration and frames the EU as a threat to the national way of life, prompting greater levels of public opposition to the European project (Taggart1998, Norris 2000, Anderson 2004, Gabel and Scheve 2006, Maier and Rittberger 2008). However, de Vreese (2007) finds that when the public is not exposed to negative media frames about European integration, public cynicism toward the EU actually decreases. Similarly, Hooghe and Marks (2004) argue that when there is not elite dissent over European integration, the public is less likely to regard the EU as a threat to national identity and more likely to consider the benefits of European integration. Given the distorting effects of Eurosceptic 
rhetoric, public opinion polls may suggest greater opposition to European integration than would exist amongst a better-informed public.

Our findings have implications for several areas of study. First, we demonstrate the vital role of political information for developing democratic institutions at the regional and global levels of governance. Partially in response to charges of a democracy deficit, the EU has empowered the European Parliament and improved the accessibility of the other EU institutions. However, such institutional reforms are not likely to improve legitimacy - in the EU or any other regional or international body - unless the public understands how a multi-level system works. Second, we examine the role of political information in an entirely different political context, finding that, while the costs of acquiring information may be different at the national and European levels, the implications of information biases are very much the same. Lastly, while recent scholarship has found that political information matters for a wide range of political phenomena, the salience of being fully informed has received little attention in evaluations of support for jurisdictional boundaries in policy-making. This study advances what we know about public opinion and European integration, both by moving beyond mere consideration of general support for integration to consider support for specific areas of policy control and, in so doing, by moving beyond debates which presently inform the literature about the utilitarian or cultural bases of support to specify where and to what extent information effects matter. ${ }^{1}$

We next review the literature on information effects at both the national and European levels and the research on support for European integration. We then develop a theory explaining

\footnotetext{
${ }^{1}$ Contributions to the debate over the utilitarian versus cultural/identity-based factors shaping support for European integration include Diez Medrano 2003, Gabel 1998a, Mahler et al. 2000, and McLaren 2002. As regards our attention to support for policy jurisdiction, we are aware of only one previous empirical study, Ray's (2004) analysis of policy benefits.
} 
why information might have a larger effect on economic positions than on other areas, and present a set of hypotheses on information effects across different policy jurisdictions. To investigate these hypotheses, we rely on data from Eurobarometer 62.0, conducted in the fall of 2004. As with other work on vote choice (Bartels 1996; Blais et al. 2009) and on policy preferences (Althaus 2003; Gilens 2001), we simulate the effects of a fully-informed citizenry on preferences for EU jurisdiction over several different social, cultural, economic, and foreign policy areas. The penultimate section probes the bases for differential effects of information across different types of issue domains. We conclude by discussing the implication of study findings for the future of European integration.

\section{Information Effects in Mass Political Attitudes}

There is a long-standing consensus that voters know very little about their political system (Converse 1964, Bennett 1988, Delli Carpini and Keeter 1996, Althaus 2003). ${ }^{2}$ However, scholars are divided over the consequences of this political ignorance. One side maintains that a largely ill-informed public does not have an adverse effect on the accuracy of collective preferences or the representational quality of a democratic system. In this camp, some scholars argue that statistical aggregation nullifies the distorting effects of ill-informed responses on collective opinion (Page and Shapiro 1992) - in other words, the preferences of different illinformed individuals are balanced out within groups. Others contend that ill-informed individuals can use heuristics to behave as if they have full information (Hurwitz and Peffley 1987; Popkin 1991; Sniderman et al 1991; Lupia and McCubbins 1998). The ill-informed may look to an informed source with similar pre-dispositions (political and media elites) or rely on a

\footnotetext{
${ }^{2}$ The basis for this conclusion comes mostly from analyses of the American electorate. For an example of a comparative assessment, see Gordon and Segura (1997).
} 
specific cognitive orientation (party identification) to identify the positions that most accurately reflect their values and interests.

The other side is skeptical that aggregation and heuristics compensate for the public's lack of information, theorizing that aggregation fails to correct for any systematic bias related to low levels of political knowledge and that elites may use strategic issue frames to lead illinformed voters away from their true preferences. Indeed, information-induced biases do not disappear in the aggregate (Althaus 1998; Bartels 1996). Moreover, low levels of political knowledge have been found to influence response stability in opinion surveys (Delli Carpini and Keeter 1996), voter preferences (Zaller 1992; Bartels 1996; Blais et al 2009), and policy preferences (Althaus 1998, Gilens 2001).

Much of the literature on political knowledge focuses is based on the American electorate. There have been few efforts to systematically examine the role of voter sophistication in comparative perspective (cf Gordon and Segura 1997). Studies of retrospective voting, however, offers some clues as to the conditions surrounding political knowledge in a multilevel context. This research finds that voters have a more difficult time attributing responsibility for policy outcomes the more that power is dispersed across different political parties and/or decision-making bodies. In particular, the larger number of political actors and more complex institutional arrangements of multi-party systems obscure which parties are to blame for policy failures. ${ }^{3}$ Europeans thus make use of a unique set of heuristics to identify the parties responsible for policy outcomes, including a party's status as member of the government or opposition, size of the party, length of time in a ruling coalition, control of important ministries, and placement on the left/right spectrum (Powell and Whitten 1993; van der Brug et al 2007; Duch and

\footnotetext{
${ }^{3}$ Consistent with these findings are studies indicating that federalism complicates the public's ability to attribute responsibility to different political actors (Arceneaux 2006; Cutler 2008).
} 
Stevenson 2008). While not directly addressing political knowledge, this research does suggest that the greater complexity of politics at the European level makes it more difficult for individuals to understand how the political system works. ${ }^{4}$

The obstacles to learning about the EU are (even) larger than those in most national political systems. EU politics involves a large number of actors, from the local, regional, national and European levels of governance and from both the public and private spheres. The EU institutions share jurisdiction with the national governments over many policy areas, obscuring who has responsibility for EU decisions. Further, the EU is governed by a large and complex body of decision-making rules, which creates ever-shifting configurations of shared power between the EU institutions, the member governments, local and regional bodies, and private actors over different policy areas. Schmitter (2000) argues that the EU’s decision-making rules are "virtually unintelligible even to experts, much less citizens," and successive Treaties have done little to remedy the situation. The complexity of EU decision-making inhibits the public from understanding or participating in EU affairs (Schmitter 2000, Christiansen 2001, Chabert 2002, Craig and DeBurca 2003).

Furthermore, Europe lacks the same quality or supply of cognitive heuristics as found at the national level. Most Europeans receive their information about EU politics not from any EUspecific source but from local and national-based media outlets that devote far more coverage to local and national issues, even when covering political events at the EU level (Meyer 1999, Anderson and McLeod 2004; de Vreese et al 2006). And in those instances when local and national media outlets do take an interest in the EU, the public is presented with one-sided often negative - accounts of EU politics (Anderson and Weymouth 1999, Norris 2000, de Vreese

\footnotetext{
${ }^{4}$ Similarly, de Vries et al. (forthcoming) find that voting on the basis of EU issues is accentuated by the clarity of national institutions.
} 
2002, Anderson 2004, de Vreese, et al 2006, Maier and Rittberger 2008). Thus, it is doubtful that the public receives consistent signals from the media about the policy content of EU affairs. Indeed, a number of studies demonstrate that low levels of information affect voting behavior at the EU level. More knowledgeable individuals appear more likely to vote in European Parliament (EP) elections (Clark 2010), and EP voters with better access to information about the EU are more likely to vote based on EU preferences, rather than act on concerns about national political issues (Hobolt and Wittrock 2010; de Vries, et al forthcoming). Hobolt (2007) similarly finds that greater levels of EU information improve voters' competence - the ability to use electoral mechanisms to address the task at hand (i.e. vote on EU issues in EU referenda). However, none of the research has yet explored the potential effect of information on attitudes toward European integration.

There are a couples reasons to suspect that better-informed citizens are more likely to support European integration. The EU offers a number of potential benefits to the member states, including substantial financial assistance to agricultural markets, region-based subsidies to improve infrastructure, access to new markets, opportunities to cooperate in foreign and diplomatic matters, and mechanisms to better address global crime, environmental pollution, and other cross-border issues. The better-informed are more likely to be aware of the EU's efforts in these areas, and to support European integration when and where there are clear benefits to their own pocketbook or to the national well-being.

High sophisticates should also be less susceptible to the cues of Eurosceptic elites who frame the EU as a threat to the national way of life. Through such discourse, political and media elites have been effective in stoking fears of the EU and creating opposition to European integration (Norris 2000, Hooghe and Marks 2004, Gabel and Scheve 2006, de Vreese 2007, 
Maier and Rittberger 2008, Bruter 2009). Negative EU frames typically rest an assumption that the EU has the power (either presently or in the future) to take control over areas traditionally under local and national control and to eventually destroy national sovereignty and the people's sense of belonging to a national community. In actuality, the EU has minimal influence over most non-economic areas, and is unable to undertake any action without the support of the member states. Those individuals with greater knowledge about the EU's history and treaties are more likely to recognize the political and legal limits on the EU's authority. Elite cues should have a minimal effect on the attitudes of better-informed individuals who, at the EU level, recognize the limits on EU power and are thus less likely to be persuaded by the rhetoric of Eurosceptic elites.

Given the greater potential for ill-informed positions at the EU level, there is reason to suspect that EU survey data does not reflect the public’s true preferences toward European integration. In the following analyses, we assess two claims. The first concerns whether information effects actually exist at the EU level. Here, we expect that collective preferences for European Union policy control are affected by biases arising from less-than-fully informed publics in the member states. The second claim pertains to the direction of these expected effects. Specifically, we expect the bias to be downward: low levels of information about the European Union are expected to cause an overall downward bias in collective preferences for EU policy control, as measured by opinion surveys.

\section{Research Design}

We are interested in the size and direction of information effects, that is, of the bias in aggregate opinion due to less-than-optimal levels of political knowledge—on mass policy 
preferences. But unlike previous work on mass policy opinions, we are not interested in preferences for or against a specific proposal like school desegregation or banning nuclear weapons (e.g., Zaller 1992). Our aim is instead to understand public preferences for the locus of policy decision-making, or policy control. Do Europe’s citizens prefer that decision-making remains under the sole jurisdiction of national authorities? Or, recognizing the effects of globalization and Europeanization, do member state publics perceive the benefits of sharing policy control with European Union officials?

To address these questions, we employ cross-national public opinion data from Eurobarometer 62.0, conducted in the fall of 2004 (Papacostas 2005). To measure citizen preferences for EU-level policymaking, we make use of a unique battery of items from Eurobarometer survey series which ask respondents whether certain policies should be at the national level or jointly with the European Union. The item is worded as follows:

Some people believe that certain areas of policy should be decided by the [NATIONAL] government, while other areas of policy should be decided jointly within the European Union. Which of the following areas of policy do you think should be decided by the [NATIONAL] government and which should be decided jointly within the European Union?

Respondents were then asked to evaluate the following policy areas: currency, jobs, research and development, environment, regional policy, agriculture, poverty, welfare, education, culture, defense, combating terrorism, foreign policy, crime, and immigration. The black vertical bars in Figure 1 display the percentage of respondents in the multi-country survey who think that decision-making for each policy should be shared with the EU. As we might expect, nearly 9 in 10 believe that fighting terrorism requires EU-level oversight, implying that an influx of information could have little effect on raising support for European policy coordination in this area. Large majorities also support EU control to fight the trade in human beings, to combat organized crime, and the fight against drugs. 


\section{$<$ Figure 1 about here $>$}

These differences across issues are interesting and, by themselves, are instructive for European policymakers seeking to identify nodes of mass political support for their endeavors. However, these top-level statistics tell us nothing in terms of the impact—if any—of a more informed European citizenry. To address this, we incorporate a measure of political information ${ }^{5}$. Eurobarometer (EB) 62.0 includes a number of true/false questions about the history and political institutions of the European Union, listed in full in Appendix A. We construct an index that tallies each respondent's number of correct response to these questions. For the most part, EB respondents are spread evenly across the seven categories in this information index, with the most respondents (23\%) answering three of the six questions correctly.

Using these data, we estimate a statistical model on the Eurobarometer survey data of the form

$$
\operatorname{prob}\left(Y_{i}=1\right)=\alpha+\beta_{1} I_{i}+\sum \beta_{k} D_{i k}+\sum \delta_{k}\left(I_{i} * D_{i k}\right)+\sum \beta_{m} C_{i m}+e_{i}
$$

where $Y_{i}$ is respondent $i$ 's preference for policy jurisdiction scored 1 if she or he says should be decided jointly within the European Union and 0 otherwise. The variable $I_{i}$ is $i$ 's score on a scale of political information described above, $D_{i k}$ is $i$ 's score on the $k$ th demographic characteristic, $I_{i}$ ${ }^{*} D_{i k}$ is the product of respondent $i$ 's information score multiplied by her score on the $k$ th demographic characteristic, and $e_{i}$ is the error term for the ith observation. The demographic characteristics, $D_{i k}$, include all a set of individual-level attributes, including education, age,

\footnotetext{
${ }^{5}$ The literature on political behavior uses a number of terms to refer to how much people know about their political system, including political information, political knowledge, political sophistication, and political interest (Price and Zaller 1993, Carpini and Keeter 1996, Price 1998). Following Carpini and Keeter (1996), we take political information and political knowledge as meaning facts about a political system that are stored in an individual's longterm memory and can be recalled to identify, interpret, and understand political events. At the EU level, a knowledgeable individual can recall facts about the history of integration, EU institutions, and the nature of shared powers between the EU and the member states
} 
gender, location (urban vs. rural), ideology, and occupation. Finally, we allow for the mean level of policy preferences to differ across the 25 member states included in the survey through the inclusion of a set of $\mathrm{m}(1,2, \ldots, 25)$ country dummy variables, $C_{i m}$.

We use observational data from the Eurobarometer surveys to simulate what an individual's policy preferences would be—either for or against EU-level control over policy—if she were “fully informed.” Before assessing how biases arising from less-than-perfect knowledge of European Union politics, we must ask whether they exist in the first place. For, as previous studies have shown, it is by no means preordained that mass behavior is subjected to information bias. ${ }^{6}$ To test for the existence of information effects in collective preferences for EU policy jurisdictions, we first estimate the unrestricted model in equation (1) for each of the 29 policy areas. We then estimate a restricted version of this model which excludes information effects. ${ }^{7}$ We test the null hypothesis for no information bias using a likelihood ratio statistic, distributed as a chi-square with degrees of freedom equal to the number of parameters in the unrestricted equation.

Results of performing this exercise for each of the 29 policy areas are reported in Table 1. Two findings are of note. First, for every policy, political information has a statistically significant impact on preferences for EU-level policy control. This result differs somewhat with studies by Bartels (1996) and Blais et al. (2009) which, in the case of vote outcomes in national elections, both find that such effects exist only in half of the cases they investigate. ${ }^{8}$ Second, Table 1 provides an initial sense of variation in information biases across issue areas. Test

\footnotetext{
${ }^{6}$ For example, Blais et al. (2009) examine six Canadian federal elections from 1988 to 2006 and find evidence for information bias in vote choice for (only) three of the six. Similarly, Bartels (1996) similarly finds no statistically significant impact for information in three of the six American elections he examines.

${ }^{7}$ The restricted model is of the general form $\operatorname{prob}\left(Y_{i}=1\right)=\alpha+\sum \beta_{k} D_{i k}+\sum \beta_{m} C_{i m}+e_{i}$.

${ }^{8}$ This finding is perhaps unsurprising for reasons both statistical, in that we have a large number of observations, and substantive, in that the average European citizen likely does not have well-crystallized opinions on the locus of policy-making authority.
} 
statistics magnitudes are largest for such areas as protection of the environment, regional policy, agriculture, and currency, and smallest for urban crime, culture, police, and education. This hints that for the former set of areas, individual knowledge about how Europe works is an important factor shaping an individual's choice to support (or not) EU-level authority. Conversely, in the latter set of areas, we would expect the acquisition of greater knowledge to have little effect in swaying opinions on whether national or European authorities ought to have policy jurisdiction.

\section{<Table 1 about here $>$}

To get a better sense of the magnitude and direction of these information biases, we compare observed levels of support for EU policy control, as reported above in Figure 1, with simulated "fully informed" support levels. To do so, we simulate fully informed opinion by taking respondent's scores on each of the $D_{i k}$ demographic characteristics and multiplying it by coefficients obtained from estimating equation (1). To each respondent we assign "full information" by substituting the maximum values on the political information scale. This effect is modeled to influence policy opinions directly and indirectly, through its impact on respondent individual attributes. Finally, all the individual fully informed opinions are aggregated into a fully informed collective preference over the locus of policy decision-making. The mean of the $Y_{i}$ probabilities are used to construct fully informed percentages supporting EU-level jurisdiction.

Results are reported for each of the policy areas in the light grey bars in Figure 1. These results show that in each of the 29 policy areas, collective preferences in support of EU control are greater in the fully informed case than in reality. In some cases, such as urban crime prevention, police, and welfare, this bias is miniscule - on the order of 2 percent or less. More often than not, however, the estimated information effect is considerable. 
The magnitude of these effects are seen more clearly in Figure 2, which displays the identical information as Figure 1 but in a single statistic by subtracting the percent supporting EU-level control taken from survey marginals from the percent supporting EU-level control under full information. Information effects range in size from 0.2 percent in the case of urban crime prevention to 22.8 percent for environmental protection. Notably, the mean difference value of 11.6 percent is nearly identical to the median of 11.7 .

$<$ Figure 2 about here $>$

\section{Why does Information Matter more for some Policy Areas than Others? Understanding Heterogeneity in Information Effects}

The results reported above give strong evidence that political knowledge matters for how mass publics think about Europe and whether they support the EU's efforts to legislate in policy competences shared with member states. How individuals perform on our battery of objective knowledge items influences their beliefs about what this still-evolving European Union should (and should not) do. The prescription for proponents of deepening integration is clear: to improve public acceptance for increased European-level policy authority, seek ways to develop a more informed European citizenry.

However, an additional key finding displayed in Figure 2 is that the extent to which information raises support for EU jurisdiction is not uniform but varies across issue areas. ${ }^{9}$ What accounts for this variation in the magnitude of information effects, and why are the policy consequences of full information greater in certain areas than others? In this section we explore these issues. We examine two possible explanations.

\footnotetext{
${ }^{9}$ It should be noted that ancillary analyses found that that issue area accounts for more of the variation in information effects than do factors specific to individual member states. We ran the simulations separately on individual country samples and found, for the most part, that the rankings of information effects to be the same as that shown in Figure 2 for the 25 separate country surveys.
} 
First, informed citizens may support EU jurisdiction in policy areas related to the single market. The EU began in the 1950s as a project to create a single European market - a goal that was renewed by European leaders in the mid-1980s. When extending the EU's influence into non-economic areas, the EU institutions have often had to justify their actions as necessary for maintaining the integrity of the single market. We suspect that the better-informed are aware of the origins and purpose of the European Community as an economic project, and are thus more willing to support the extension of EU authority in areas that are clearly related to the single market. Additionally, the most visible benefits of European integration are economic - subsidies, participation in the single market. The more informed Europeans are about these potential benefits, the more likely they might be to support EU authority over the economy.

This explanation is consistent with arguments, prominent in the public opinion literature, which assert that support for the EU is due to the economic consequences of integration (Eichenberg and Dalton 1993, Anderson and Kaltenhaler 1996, Gabel 1998a, Mahler, et al 2000). EU supporters are those in the best position to make financial gains from economic integration, either because they have the knowledge and skill-sets to be competitive in an enlarged work-force (Gabel and Palmer 1995, Anderson and Reichert 1995, Duch and Taylor 1997, Gabel 1998b) or sufficient capital to pursue low-risk investment opportunities in expanded markets (Scheve 2000, Gabel 2001). Additionally, the perception that European integration benefits the national economy also encourages pro-EU attitudes. Those countries that trade more frequently with EU partners and receive a greater proportion of EU subsidies demonstrate higher aggregate levels of EU support (Anderson and Reichert 1995, Brinegar, et al 2004, Eichenberg and Dalton 2007). 
This research has been criticized for overlooking the cultural underpinnings of EU support. Some scholars argue that individuals who closely identify with their national community are more likely to view the $\mathrm{EU}$ is a threat to the national way of life and to oppose European integration (Carey 2002, Christin and Trechsel 2002, McLaren 2002). Others maintain that strong national identities enhance support for the EU pro-EU attitudes. Individuals are not only able to simultaneously identify with regional, national, and European communities (Marks 1999, Habermas 2001b, Diez Medrano 2003), but multiple identities serve to reinforce one another (van Kersbergen 2000, Haesly 2001, Klandermans, et al 2003). More recent contributions suggest that both economic and cultural-based factors may explain EU support under different conditions (Hooghe and Marks 2004, Maier and Rittberger 2008, Garry and Tilley 2009).

Part of the reason that this research agenda has produced these conflicting explanations is that scholars often rely on a very limited understanding of EU support. Many scholars focus on broad support for European integration - the most common measure being the Eurobarometer survey question that asks respondents whether they think their country's membership in the EU is "a good thing" or "a bad thing". This approach does not recognize the potential nuance in the public's views on European integration. Individuals may both support and oppose efforts at integration, depending on the policy domain. Farmers, for example, may support EU influence over agricultural policy due to the significant EU subsidies and market protections, but oppose any integration that displaces more proximate control of, say, education or law enforcement. A better-informed public may thus support EU jurisdiction over policies clearly related to the single market more than other areas of European integration. 
Second, informed individuals may support EU authority over problems that can best be addressed through regional cooperation. EU members (indeed all countries in the world) must often cope with problems that have extraterritorial origins and which, almost by definition, cannot be addressed by the actions of a single state. Asylum seekers fleeing persecution, policies to counter international terrorism, immigration, and many other issues require regional and global solutions. At least some members of the public are aware of the inability of national governments to effectively deal with such problems (see, e.g., Hellwig et al. 2008). We assess whether the better-informed may be more likely to recognize the constraints on state power, and to support EU competencies in policy areas concerned with cross-border or regional problems.

To identify the type of policies that most benefit from greater levels of information, we estimate a model of fully-informed support for EU jurisdictional authority. The dependent variable, Full Information Effect, is equal to the difference between simulated support levels and actual support levels for the EU to have at least some jurisdiction in each of the 27 different policy areas, as shown in Figure 2. Full Information Effect is regressed on Actual Support for EU policy control (see black bars in Figure 1) and two indicator variables. The first indicator, Single Market Policy, is scored 1 for those issue domains included as part of the single market (unemployment, Support for regions, Science and technological research, Agriculture and fisheries, and Currency Policy) and 0 otherwise. The other, Cross-Border Policy, is coded 1 for policy areas which addresses a cross-border or regional problem (terrorism, drugs, organized crime, human trade, foreign policy, asylum, defense, immigration, refugees, and humanitarian aid) and 0 otherwise. In addition, we include a measure for Protection of the Environment, as this issue does not fall neatly into either of the categories. All other issue domains are left uncoded and serve as the baseline category for analysis. 
The OLS results of this analysis model are presented in Table 2. The first model simply regresses Full Information Effect on actual support levels. We see that, all else equal, the role of objective knowledge about Europe plays a stronger role in increasing support for European jurisdiction in those areas which already enjoy some level of support. The second model distinguishes between types of policy. As reasoned above, information matters more than average for domains associated with cross-border political issues. Specifically, the coefficient of 7.6 implies that the influence of a fully-informed EU citizenry on support for EU-level competencies is about 8 percent stronger for cross-border issues than for issues in general. The coefficient on Single Market Policy is also positive but does not reach conventional levels of statistical significance. This analysis provides preliminary evidence that an informed European public would support greater EU authority in some areas more than others.

\section{$<$ Table 2 about here $>$}

\section{Conclusion}

Simulating the collective preferences of a better-informed European public, we find that low levels of information about the EU distort attitudes toward European integration. An informed European public would support European integration more than is currently indicated in mass survey data. These results have clear implications for discussions about EU democracy. EU critics often focus on the lack of democratic accountability within EU decision-making. In recent years, the member states and EU institutions have responded with institutional reforms designed to empower the European Parliament, increase the transparency of EU decisionmaking, and further open the EU institutions to public oversight. Such efforts may be in vain without any corresponding increase in the public's awareness of EU politics. Indeed, to the 
extent that the 'democracy deficit' is defined by the EU's low legitimacy, our findings suggest that the public's relative ignorance about the EU may be the real source of the problem.

This analysis demonstrates larger information effects on political attitudes than found in prior research (Althaus 1998; Bartels 1996). We speculate this may be due to two reasons. First, as we argued earlier in the chapter, the obstacles to learning about the EU are much higher than at the national level. The EU is a complex political system, involving a multitude of actors and governed by decision-making rules that seem to be in constant flux. Moreover, there seem to be fewer, less reliable sources of information (the media or political elites) on EU politics. As such, it is not surprising to find evidence of a larger information bias in EU public opinion. Our findings suggest that future research on the effects of political information should take into account variation in institutional complexity across different types of political systems.

Second, we look at the public's preferences for which actors hold jurisdictional authority and not the direction of policy - for instance, which actor(s) does the public want to have decision-making authority over the environment, rather than if the public thinks the government should do more or less about the environment. There may be a stronger relationship between political information and jurisdictional preferences than between information and policy preferences. For many people, political ideology and partisanship act as filters for political information - when an individual receives information (whether from a biased or objective sources), they interpret that information in light of their ideological or partisan beliefs. We expect that partisanship and ideology provide more interpretive cues for left/right political issues than policy jurisdictions, and thus do not play as much of an intermediary role between information and jurisdictional preferences. 
Moreover, many measures of political information - including the one in this study - are focused on an individual's knowledge of the political process more than their awareness of political issues. Indeed, better-informed individual are likely to know about process before politics. When a student learns about their political system in a civics or government class, it is generally to learn the difference between the executive and legislature and not the position of the center-right party on the environment. We should thus expect information to have a larger effect on preferences about the political process - in this case, the EU's role in policy-making - than political issues. Our findings indicate that research on information effects would benefit from looking at different types of political attitude, to better understand the role of information in the public's relationship with their political system.

Finally, our results suggest that further work might explore how better-informed individuals decide when and why to support European integration. The research seeking to explain support for the EU argues that individuals consider whether the EU offers any economic gain or whether European integration poses any risk to national culture. However, in focusing entirely on broad support for the European project, this work overlooks the possibility that the public supports integration in some policy areas more than others. We examine differences in support across different policy areas, finding some preliminary evidence that information has a greater effect on support for EU authority in areas involving cross-border or regional issues. There are a number of other possible considerations that shape jurisdictional preferences, such as which political actor has the legal basis to assume jurisdiction or which actor has demonstrated the most competence in decision-making. Many of these considerations may interact to influence better-informed preferences, and could shed further light on how individuals develop positions in a multi-level system of governance. 


\section{Appendix A. Survey Measures}

Knowledge Scale:

Each respondent's score is based on the number of correct responses to the following questions.

For each of the following statements about the European Union could you please tell me whether you think it is true or false?

1. The European Union currently consists of twelve Member States

2. The Members of the European Parliament are directly elected by the citizens of the European Union

3. The President of the European Commission is directly elected by the citizens of the European Union

4. The European Union has its own anthem

5. Each year, there is a Europe Day in all the countries of the European Union

6. The last European elections have taken place in June 2002

\section{Coding for Policy Area Indicators for analysis in Table 2}

Single Market Policies:

Fight against unemployment

Support for regions

Science and technological research

Agriculture and fishing policy

Currency

Cross-Border Policies:

Fight against international terrorism

Fight against drugs

Fight against organized crime

Fight against human trade

Rules for political asylum

Foreign policy towards countries outside EU

Defense

Immigration policy

Accepting refugees

Humanitarian aid 
Table 1. Tests for Presence of Information Effects in Models for Support for European Union Policy Jurisdiction

\begin{tabular}{lr}
\hline Policy Area (dependent variable) & Test statistic \\
\hline Fight against international terrorism & 449.73 \\
Fight against human trade & 463.24 \\
Fight against organized crime & 433.56 \\
Fight against drugs & 339.34 \\
Information about the European Union & 390.49 \\
Science and technological research & 330.40 \\
Humanitarian aid & 320.38 \\
Foreign policy towards countries outside EU & 334.61 \\
Protection of the Environment & 627.75 \\
Support for regions & 562.50 \\
Currency & 483.53 \\
Fight against poverty & 350.11 \\
Defense & 258.63 \\
Immigration policy & 235.82 \\
Rules for political asylum & 279.18 \\
Fight against unemployment & 276.27 \\
Accepting refugees & 236.52 \\
Agriculture and fishing policy & 542.12 \\
Tackling challenges of ageing population & 329.67 \\
Juvenile crime prevention & 128.11 \\
Education & 162.43 \\
Health and social welfare & 207.49 \\
Justice & 188.14 \\
Urban crime prevention & 91.84 \\
Rules for broadcasting and the press & 192.91 \\
Cultural policy & 111.50 \\
Police & 111.51 \\
\hline
\end{tabular}

Notes: Cells report results of a likelihood ratio test of the null hypothesis that the joint effect of Political Information on support for EU-level policy jurisdiction is zero. Test statistics are distributed as chi-square with 14 degrees of freedom. All reported statistics are statistically significant at $p<.001$. 
Table 2: Modeling Fully Informed Support for EU-Level Policy Competencies

\begin{tabular}{lcc}
\hline & Model 1 & Model 2 \\
\hline Actual Support & $0.15^{* *}$ & -0.005 \\
& $(0.06)$ & $(0.09)$ \\
Single Market Policy & & 4.63 \\
& & $(3.07)$ \\
Cross-Border Policy & & $7.58^{* *}$ \\
& & $(3.01)$ \\
Protection of Environment & & $15.47^{* *}$ \\
& & $(2.66)$ \\
Constant & 3.31 & $7.63^{*}$ \\
$R^{2}$ & $(3.69)$ & $(3.85)$ \\
$\mathrm{N}$ & 0.19 & 0.48 \\
\hline
\end{tabular}

Note: Entries are coefficients from an OLS analysis on 27 policy areas with robust standard error in parentheses. $* *$ denotes significance at $.05, *$ denotes significance at .10 .

Source: Eurobarometer 62.0 
Figure 1. Public Support for Joint Policy Control with the European Union, 2004

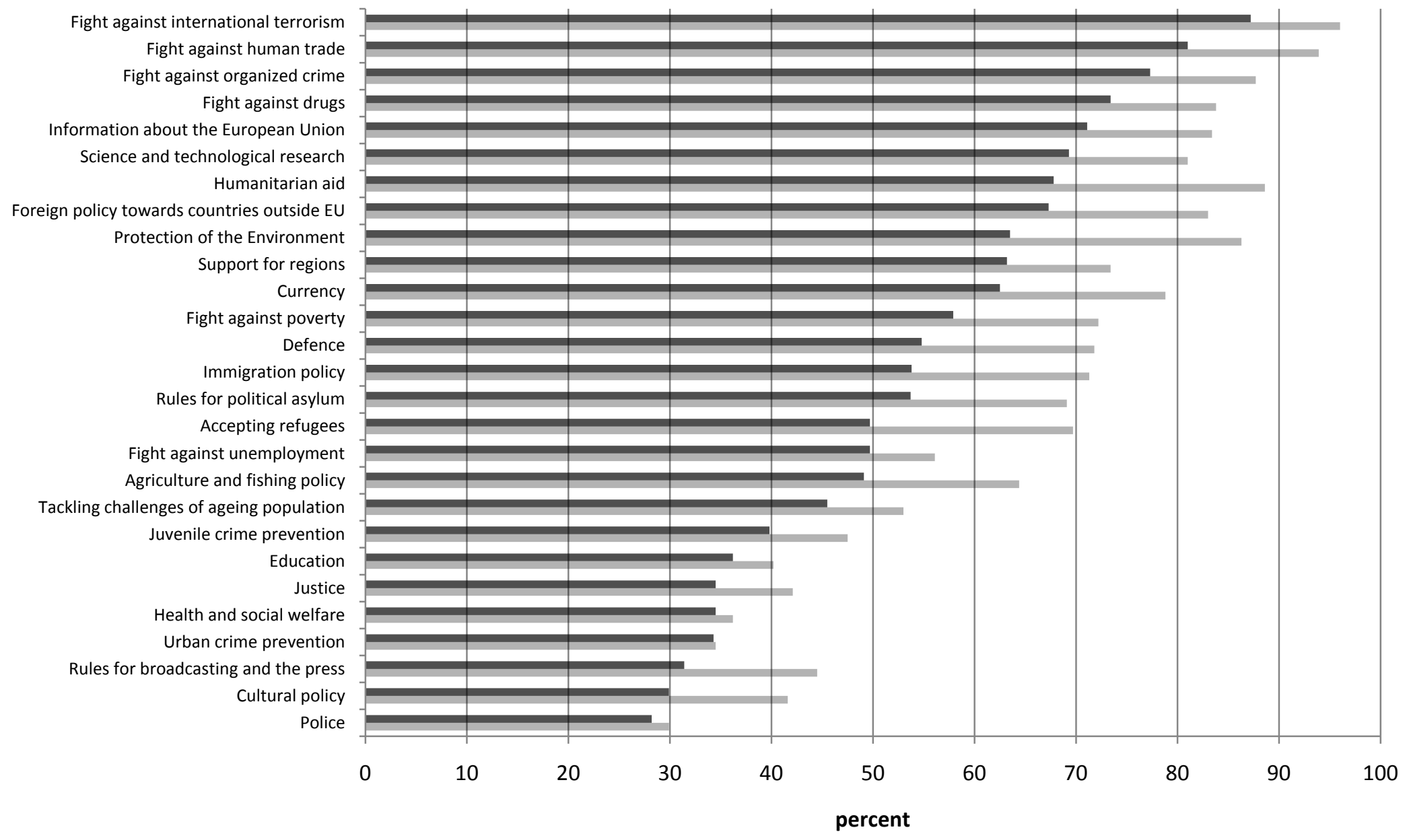

- Support for EU policy control $\quad$ Full Information support for EU policy control

Notes: Figure displays percentage of respondents who believe decisions in given policy area should be decided jointly within the European Union as provided by survey marginals (black bars) and by simulated full information effects (grey bars). Source: Eurobarometer 62.0. 
Figure 2. Magnitude and Direction of Effect of Political Information on Collective Preferences for Joint Policy Control with the European Union, 2004

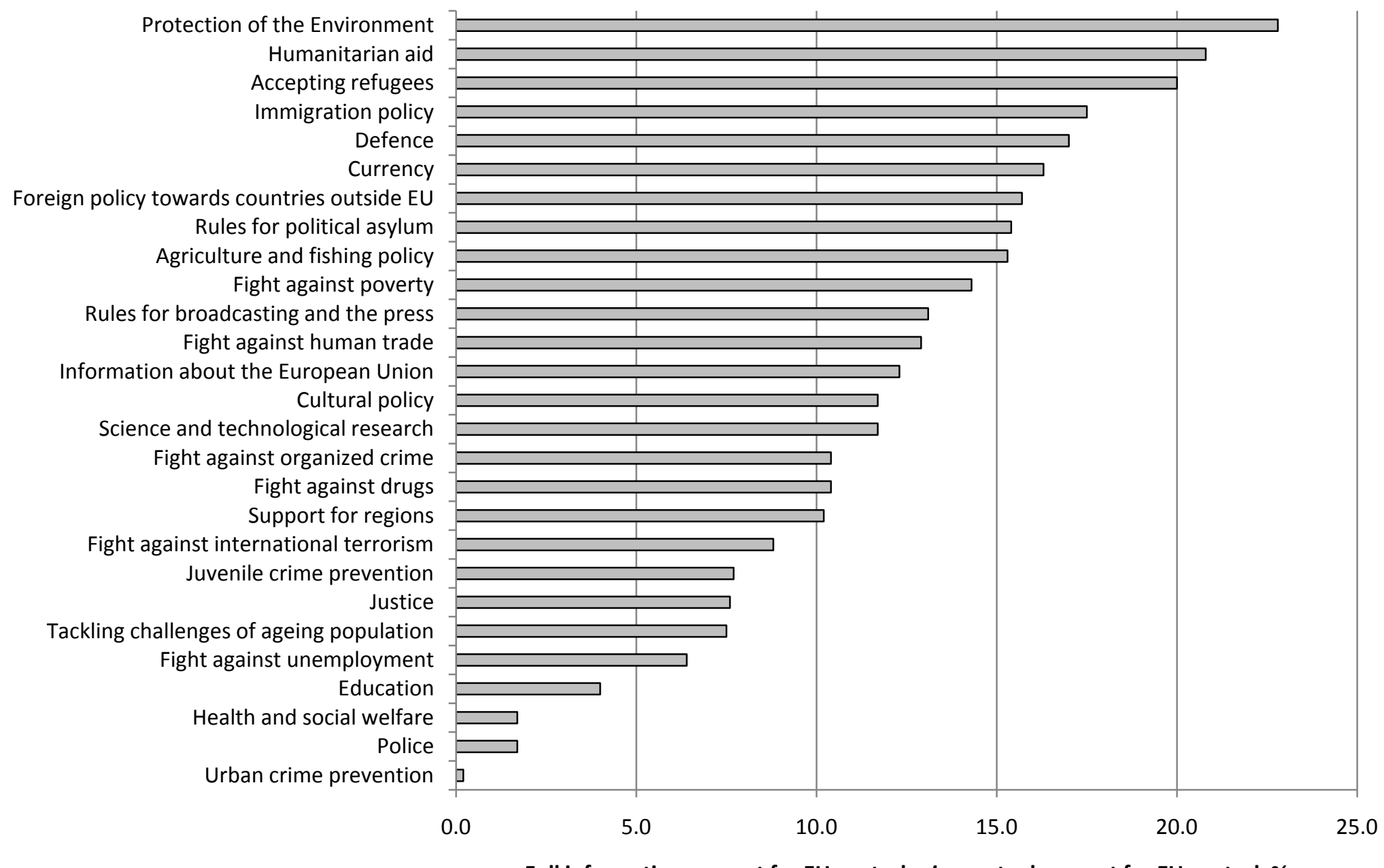

Full information support for EU control minus actual support for EU control. \%

Notes: Figure displays the difference in the full information-simulated percentage of respondents who believe decisions in given policy area should be decided jointly within the European Union and the percentage as provided by survey marginals. Source: Eurobarometer 62.0. 